\title{
Níveis de teonina em rações para tilápias-do-nilo ${ }^{1}$ \\ Lilian Carolina Rosa Silva², Wilson Massamitu Furuya ${ }^{3}$, Lilian Dena dos Santos ${ }^{2}$, Vivian Gomes dos Santos ${ }^{4}$, Tarcila Souza de Castro e Silva ${ }^{4}$, Priscila Juliana Pinsetta ${ }^{4}$
}

\author{
${ }^{1}$ Parte da dissertação apresentada à Universidade Estadual de Maringá pela primeira autora. \\ 2 Mestranda em Zootecnia da Universidade Estadual de Maringá. \\ 3 Departamento de Zootecnia da Universidade Estadual de Maringá \\ 4 Graduanda em Zootecnia da Universidade Estadual de Maringá.
}

RESUMO - Este estudo foi realizado para determinar a exigência de treonina para tilápia-do-nilo. Os peixes (37,61 $\pm 1,16 \mathrm{~g}$ de peso inicial) foram distribuídos em um delineamento inteiramente casualizado, com quatro tratamentos, três repetições e 25 peixes por unidade experimental. Foi utilizada uma ração-referência $(27 \%$ de PB e $3.000 \mathrm{kcal}$ de ED $/ \mathrm{kg})$ suplementada com L-treonina, resultando em rações com 0,$92 ; 1,06 ; 1,21$ e 1,35\% de treonina total. Os aminoácidos sintéticos foram adicionados para manutenção do perfil de aminoácidos, de acordo com o conceito de proteína ideal. Os peixes foram alimentados até saciedade aparente durante 110 dias. Não foram observados efeitos dos níveis de treonina nas rações sobre o consumo de ração, o peso do fígado, o índice hepato-somático, os rendimentos de carcaça e de filé e a composição do filé em água (PB e EE). Constatou-se aumento linear sobre o ganho de peso, a conversão alimentar, a taxa de eficiência protéica, a retenção de nitrogênio, os pesos da carcaça e do filé e o teor de cinzas no filé. Considerando os resultados de desempenho, de custo/kg de ganho de peso e de custo/kg de peso em filés, pode-se inferir que tilápias-do-nilo de 38 a 351 g criadas em tanques-rede necessitam de $1,35 \%$ de treonina na ração $-5,51 \%$ da proteína digestível ou $74 \%$ de lisina (com base no conceito de proteína ideal).

Palavras-chave: aminoácidos, desempenho, Oreochromis niloticus, peixes, rendimento de carcaça

\section{Threonine levels in diets for Nile Tilapia}

\begin{abstract}
This experiment was conducted to determine the dietary threonine requirements for Nile tilapia. The fishes $(37.61 \pm 1.16$ of initial weight) were allotted to a completely randomized design with four treatments, three replicates and 25 fishes per experimental unit. It was used a reference diet with $27 \%$ of CP and $3,000 \mathrm{kcal}$ of DE/ $\mathrm{kg}$, supplemented with L-threonine, resulting in diets with $0.92,1.06,1.21$, and $1.35 \%$ of total threonine. Synthetic amino acids were added to mantain their profile according to the ideal protein concept. Fishes were fed ad libitum during 110 days. No effects of dietary threonine levels on feed intake, liver weight, hepatic somatic index, carcass yield, fillet yield and fillet water composition (CP and EE) were observed. It was observed linear increase on weight gain, feed:gain ratio, protein efficiency rate, nitrogen retention, carcass weight, fillet weight and ash content in fillet. Considering data of performance, cost $/ \mathrm{kg}$ of weight gain and cost $/ \mathrm{kg}$ of fillet weight, the dietary total threonine requirement is of $1.35 \%$ [ $5.51 \%$ of digestible protein or $74 \%$ of lysine (based on the ideal protein concept)] for Nile tilapia from 38 to $351 \mathrm{~g}$, reared in net pens.
\end{abstract}

Key Words: amino acid, carcass yield, fishes, Oreochromis niloticus, performance

\section{Introdução}

A tilápia-do-nilo (Oreochromis niloticus) é considerada uma das espécies mais promissoras para a piscicultura, pelo rápido crescimento em criações intensivas, pela facilidade de obtenção de larvas e pela rusticidade. Entre as espécies de água doce não-carnívoras, a tilápia tem se destacado pela elevada capacidade em utilizar a energia e os nutrientes dos alimentos de origens vegetal e animal, o que possibilita a elaboração de rações práticas de baixo custo e elevado valor nutritivo.
Os aminoácidos sintéticos são utilizados para suplementar rações, principalmente quando a farinha de peixe é substituída por fontes protéicas alternativas. Segundo Yamada et al. (1981), o menor desempenho obtido com peixes recebendo aminoácidos sintéticos pode ser atribuído à sua rápida absorção, com súbita elevação dos níveis plasmáticos, atingindo o pico mais precocemente que os peixes alimentados com proteína intacta do alimento, que eleva o catabolismo e sua excreção (Lim, 1993).

O alto nível de treonina na ração, no entanto, resulta em redução no consumo de ração e, conseqüentemente, em 
menor crescimento. A dificuldade de oxidação do excesso desse aminoácido e a redução da secreção de serotonina no cérebro, decorrente do aumento da concentração de treonina, podem induzir a menor ingestão de alimentos e, portanto, devem ser consideradas para se evitar a redução no desempenho (Henry \& Sève, 1993).

Existem poucos estudos envolvendo a determinação da exigência de treonina para peixes de espécies diversas criados em diferentes condições ambientais. Estudos com peixes carnívoros demonstraram grandes variações nas exigências de treonina, como o realizado por Keembyehetty \& Gatlin (1997), que determinaram valor de 1,0\% de treonina na ração (2,86\% da PB da ração) para alevinos de híbridos de striped bass (Morone chrysops x M. saxatilis) e de 0,90\% (2,57\% da proteína da ração) para juvenis.

Para juvenis de sea bass (Dicentrachus labrax), Tibaldi \& Tulli (1999) encontraram exigência de 1,22\% de treonina na ração (2,51\% da proteína da ração), valor semelhante ao descrito por Akiyama et al. (1985) para o salmão chum (Oncorhynchus keta), de 1,20\% de treonina na ração (3,04\% da PB), e inferior ao obtido por Ahmed et al. (2004) em estudo com a carpa (Cirrhinus mrigala), de 1,80\% de treonina da ração (4,5\% da $\mathrm{PB}$ da ração), atribuído ao maior ganho de peso e à melhor conversão alimentar.

Em estudos com espécies não-carnívoras, foram obtidos valores de $0,50 \%$ de treonina na ração $(2,08 \%$ da PB) para juvenis de bagre do canal (Ictalurus punctatus) (Wilson et al., 1978); de 1,05\% (3,75\% da PB) para tilápiado-nilo (Santiago \& Lovell, 1988); de 1,80\% (4,50\% da PB) para o milkfish (Chanos chanos) (Borlongan, 1991); e de $1,98 \%$ (4,95\% da PB) para a catla (Catla catla) (Ravi \& Devaraj, 1991). Esses autores observaram que o fornecimento de rações deficientes em treonina ocasionou diminuição no consumo de ração e no crescimento, piora na conversão alimentar e redução na retenção de nitrogênio.

São escassas as informações sobre as exigências de treonina em rações para tilápia-do-nilo em terminação alimentadas com rações práticas. Em rações para aves e suínos, a suplementação de treonina está estreitamente relacionada ao aumento no rendimento de cortes nobres e à redução na deposição de gordura corporal. Os estudos também têm demonstrado que a exigência de treonina para maximização do rendimento de carcaça é superior àquela para máximo incremento de peso vivo (Blás et al., 2004).

A determinação da exigência de treonina é essencial para a adequada suplementação de aminoácidos e/ou a combinação de ingredientes visando ao melhor balanceamento de aminoácidos e, conseqüentemente, ao maior desempenho produtivo dos peixes.
Este estudo foi realizado com o objetivo de determinar a exigência de treonina para tilápia-do-nilo (Oreochromis niloticus) com base no desempenho produtivo, no rendimento de carcaça e na análise econômica ( $\mathrm{R} \$ \mathrm{~kg}$ de ganho de peso e $\mathrm{R} \$ / \mathrm{kg}$ de ganho em filés).

\section{Material e Métodos}

O experimento foi realizado no período de janeiro a abril de 2004, por meio da Universidade Estadual de Maringá, na Chácara Hikari, município de Paiçandu - PR.

Foram utilizados 300 peixes (peso vivo inicial de 37,61 $\pm 1,16 \mathrm{~g}$ ) da linhagem tailandesa, revertidos durante a fase larval, provenientes da Piscicultura Araucária Belmonte, localizada em Rolândia - PR. Os peixes foram distribuídos em um delineamento inteiramente casualizado, com 12 parcelas compostas de tanques-rede retangulares (volume útil unitário de 2,0 $\mathrm{m}^{3}$ ), distribuídos em um tanque de terra $\left(2.000 \mathrm{~m}^{2}\right)$.

As rações experimentais foram formuladas com base nos valores de aminoácidos totais determinados para a espécie (Furuya et al., 2001) e acrescidas de L-treonina nas proporções de 0,$00 ; 0,15 ; 0,30$ e $0,45 \%$ da ração, para obtenção de rações com 0,$92 ; 1,06 ; 1,21$ e 1,35\% de treonina total (Tabelas 1 e 2). O milho, o farelo de soja, o farelo de trigo e a farinha de peixe foram moídos até atingirem diâmetro igual ou inferior a $0,36 \mathrm{~mm}$. As rações foram extrusadas na Fazenda Experimental de Iguatemi (Universidade Estadual de Maringá) e desidratadas em estufa de ventilação forçada a $55^{\circ} \mathrm{C}$ durante 6 horas, obtendo-se péletes com $2,5 \mathrm{~mm}$ (30 a $150 \mathrm{~g}$ de PV) e $4 \mathrm{~mm}$ de diâmetro ( $150 \mathrm{~g}$ até abate).

$\mathrm{O}$ arraçoamento foi feito manualmente, três vezes/dia (às 8,14 e 18h), até saciedade aparente, quando não era observada a captura dos grânulos. Todos os peixes foram pesados aos 60 dias do experimento para ajuste do tamanho dos grânulos da ração a ser fornecida.

As análises químico-bromatológicas das rações e das carcaças foram realizadas no Laboratório de Análise de Alimentos do Departamento de Zootecnia da Universidade Estadual de Maringá, segundo metodologia descrita por Silva \& Queiroz (2002).

Todos os peixes foram pesados no início e ao final do experimento e, após a pesagem final, foram utilizados para avaliação do ganho de peso e do rendimento de carcaça e para a análise macroscópica do fígado. Para esse exame, foram realizadas três incisões, uma paralela ao dorso, na região abdominal ventral, e duas no sentido dorso-ventral, sendo uma próxima ao opérculo. Após retirada das vísceras para determinação do rendimento de carcaça inteira, o 
Tabela 1 - Composição percentual das rações experimentais contendo níveis crescentes de treonina para a tilápiado-nilo

Table 1 - Ingredient composition of the experimental diets with increasing threonine levels for Nile tilapia

\begin{tabular}{|c|c|c|c|c|}
\hline \multirow[t]{2}{*}{$\begin{array}{l}\text { Ingrediente } \\
\text { Ingredient }\end{array}$} & \multicolumn{4}{|c|}{$\begin{array}{c}\text { Nível de treonina (\%) } \\
\text { Threonine level }\end{array}$} \\
\hline & 0,92 & 1,06 & 1,21 & 1,35 \\
\hline Milho & 38,33 & 38,48 & 38,62 & 38,76 \\
\hline Corn & & & & \\
\hline Farelo de soja & 44,50 & 44,20 & 43,80 & 43,40 \\
\hline $\begin{array}{l}\text { Soybean meal } \\
\text { Farelo de trigo } \\
\text { Wheat meal }\end{array}$ & 8,00 & 8,00 & 8,00 & 8,00 \\
\hline $\begin{array}{l}\text { Farinha de peixe } \\
\text { Fish meal }\end{array}$ & 4,00 & 4,00 & 4,00 & 4,00 \\
\hline $\begin{array}{l}\text { Fosfato bicálcico } \\
\text { Dicalcium phosphate }\end{array}$ & 1,90 & 1,90 & 1,90 & 1,90 \\
\hline $\begin{array}{l}\text { Óleo de soja } \\
\text { Soybean oil }\end{array}$ & 2,00 & 2,00 & 2,10 & 2,20 \\
\hline $\begin{array}{l}\text { L-treonina } \\
\text { L-threonine }\end{array}$ & 0,00 & 0,15 & 0,30 & 0,45 \\
\hline $\begin{array}{l}\text { DL-metionina } \\
\text { DL-methionine }\end{array}$ & 0,20 & 0,20 & 0,20 & 0,20 \\
\hline $\begin{array}{l}\text { L-lisina } \\
\text { L-lysine }\end{array}$ & 0,15 & 0,15 & 0,16 & 0,17 \\
\hline $\begin{array}{l}\text { Supl. min. e vitamínico }{ }^{1} \\
\text { Vit. and mineral mix }\end{array}$ & 0,50 & 0,50 & 0,50 & 0,50 \\
\hline $\begin{array}{l}\text { Vitamina } \mathrm{C}^{2} \\
\text { Vitamin } C\end{array}$ & 0,05 & 0,05 & 0,05 & 0,05 \\
\hline BHT $^{3}$ & 0,02 & 0,02 & 0,02 & 0,02 \\
\hline Sal comum & 0,35 & 0,35 & 0,35 & 0,35 \\
\hline $\begin{array}{l}\text { Salt } \\
\text { Total }\end{array}$ & 100,00 & 100,00 & 100,00 & 100,00 \\
\hline
\end{tabular}

1 Suplemento mineral e vitamínico (vitamin and mineral mix) (Supremais): composição por $\mathrm{kg}$ (composition per $\mathrm{kg}$ ): vit. $\mathrm{A}=1200.000 \mathrm{UI}$; vit. D3 = 200.000 UI; vit. $\mathrm{E}=12.000 \mathrm{mg}$; vit. $\mathrm{K} 3=2.400 \mathrm{mg}$; vit. $\mathrm{B} 1=4.800 \mathrm{mg}$; vit. $B 2=4.800 \mathrm{mg}$; vit. $B 6=4.000 \mathrm{mg}$; vit. $\mathrm{B} 12=4.800 \mathrm{mg}$; ác. fólico $($ folic acid $)=1.200 \mathrm{mg}$; pantotenato de Ca $($ pantothenic calcium $)=12.000 \mathrm{mg}$; vitamina $\mathrm{C}($ vitamin $C)=48.000 \mathrm{mg}$; biotina (biotin) $=48 \mathrm{mg}$; colina (choline) = $65.000 \mathrm{mg}$; niacina $($ niacin $)=24.000 \mathrm{mg} ; \mathrm{Fe}=10.000 \mathrm{mg} ; \mathrm{Cu}=600 \mathrm{mg}$; $\mathrm{Mg}=4.000 \mathrm{mg} ; \mathrm{Zn}=6.000 \mathrm{mg} ; \mathrm{I}=20 \mathrm{mg}$; $\mathrm{Co}=2 \mathrm{mg}$ e Se $=20 \mathrm{mg}$;

2 Vitamina C (vitamin C): sal cálcica 2-monofosfato de ácido ascórbico com ( $42 \%$ de princípio ativo) (calcium salt, 2-monophosphate of ascorbic acid, $42 \%$ active principle).

3 Butil Hidroxi Tolueno (Butil-hidroxi-toluen). fígado foi pesado em balança analítica $(0,0001 \mathrm{~g})$ para determinação do índice hepato-somático.

A taxa de eficiência protéica foi calculada de acordo com a expressão descrita por Jauncey \& Ross (1982):

$$
T E P=\frac{G P}{P C}
$$

em que: TEP $=$ taxa de eficiência protéica; $\mathrm{GP}=$ ganho de peso $(\mathrm{g}) ; \mathrm{PC}=$ proteína consumida $(\mathrm{g})$.

A cada semana, foram tomadas as medidas de temperatura ( 8 e $16 \mathrm{~h})$ e oxigênio dissolvido $(\mathrm{mg} / \mathrm{L})$ da água de cada tanque. Os dados foram obtidos por meio de kit digital portátil, sendo registrados valores de $28,53 \pm 1,76^{\circ} \mathrm{C}$ e $5,70 \pm$ $1,07 \mathrm{mg} / \mathrm{L}$, que se encontram dentro da faixa recomendada por Popma \& Green (1990) para peixes tropicais de água doce.

Os peixes foram distribuídos em um delineamento inteiramente casualizado, com quatro tratamentos e três repetições, considerando-se cada tanque de $2,0 \mathrm{~m}^{3}$ com 25 peixes uma unidade experimental. As análises estatísticas dos dados foram realizadas de acordo com o programa SAEG (Euclydes, 1983).

\section{Resultados e Discussão}

Na Tabela 3, encontra-se descrita a composição química das ração-referência. A relação energia:proteína da ração foi próxima à recomendada pelo NRC (1993), assim como os demais valores dos nutrientes que compuseram a ração. $\mathrm{Na}$ Tabela 4, encontram-se os valores de desempenho de tilápias-do-nilo alimentadas com rações contendo níveis crescentes de treonina.

Tabela 2 - Composição calculada de alguns aminoácidos essenciais das rações contendo níveis crescentes de treonina para tilápiado-nilo (com base na matéria natural)

Table 2 - Calculated composition of some essential amino acids of diets with increasing threonine levels for Nile tilapia (as-fed basis)

\begin{tabular}{lcccc}
\hline $\begin{array}{l}\text { Aminoácido } \\
\text { Amino acid }\end{array}$ & \multicolumn{3}{c}{$\begin{array}{c}\text { Nível de treonina (\%) } \\
\text { Threonine level }\end{array}$} \\
\cline { 2 - 5 } & 0,92 & 1,06 & 1,21 & 1,35 \\
\hline Metionina + cistina (Methionine + cystine) & 0,79 & 0,78 & 0,78 & 0,78 \\
Metionina (Methionine) & 0,45 & 0,45 & 1,41 & 0,45 \\
Lisina (Lysine) & 1,41 & 1,41 & 1,21 & 1,40 \\
Treonina (Threonine) & 0,92 & 1,06 & 0,28 & 0,28 \\
Triptofano (Thryptophan) & 0,29 & 0,29 & 0,86 & 0,96 \\
Treonina/lisina (Threonine/lysine) & 0,65 & 0,75 & & \\
\hline
\end{tabular}

\footnotetext{
1 Segundo Furuya et al. (2001) (According to Furuya et al., 2001).
} 
Não foi observada mortalidade durante o período experimental. Os níveis de treonina nas rações não influenciaram ( $\mathrm{P}>0,05)$ o peso final, o consumo, o índice hepato-somático, o peso do fígado e os rendimentos de carcaça e de filé. Em estudos realizados com sea bass europeu, Tibaldi \& Tulli (1999) também não observaram efeitos da adição de treonina sobre o consumo de ração. Neste estudo, embora não tenham sido observadas diferenças significativas dos níveis de treonina no consumo, constatou-se menor consumo de ração nos tratamentos com níveis mais elevados de treonina $(1,21$ e 1,35\%), o que pode estar relacionado, entre outros fatores, à redução da secreção de serotonina no cérebro, ocasionada pelo aumento da concentração de treonina (Henry \& Sève, 1993).

A morfologia do fígado dos peixes não foi alterada pelos níveis de treonina na ração. Verificou-se padrão de normalidade nos fígados analisados, observando-se coloração castanho-clara e lobos bem definidos em todos os peixes amostrados.

Com o aumento da suplementação de treonina, houve aumento linear $(\mathrm{P}<0,05)$ no ganho de peso (Figura 1$)$.

Corroborando os resultados obtidos por Tibaldi \& Tulli (1999) em juvenis de sea bass, verificou-se que o menor crescimento dos peixes alimentados com a ração deficiente em treonina $(0,92 \%)$ não foi ocasionado pela redução do consumo de ração. Esses autores observaram que o ganho de peso foi reduzido somente com níveis acima de 2,20\% de treonina na ração. Neste estudo, a não-redução no ganho de peso a partir de determinado nível de inclusão de treonina provavelmente está relacionada aos níveis de inclusão desse aminoácido, que foram inferiores aos utilizados pelos autores supracitados.

Verificou-se efeito linear $(\mathrm{P}<0,05)$ dos níveis de treonina da ração sobre a conversão alimentar, que melhorou com o aumento desse aminoácido (Tabela 4).

Tabela 3 - Composição química e valores de energia da raçãoreferência (com base na matéria natural)*

Table 3 - Chemical composition and energy values of the basal diet (as-fed basis)

\begin{tabular}{lc}
\hline $\begin{array}{l}\text { Composição } \\
\text { Composition }\end{array}$ & $\begin{array}{c}\text { Ração-referência } \\
\text { Reference diet }\end{array}$ \\
\hline Matéria seca (Dry matter) (\%) & 92,87 \\
Energia bruta (Gross energy) (kcal/kg) & 4.081 \\
Energia digestível (Digestible energy) (kcal/kg) & 3.200 \\
Proteína bruta (Crude protein) (\%) & 27,24 \\
Proteína digestível (Digestible protein) (\%) & 24,48 \\
Fibra bruta (Crude fiber) (\%) & 3,18 \\
Extrato etéreo (Ether extract) (\%) & 5,68 \\
Cálcio (Calcium) (\%) & 0,84 \\
Fósforo total (Total phosphorus) (\%) & 1,47 \\
Cinzas (Ash) (\%) & 6,77 \\
\hline
\end{tabular}

* Valores determinados em laboratório (LANA-UEM, Maringá - PR) (Determined values of laboratory).

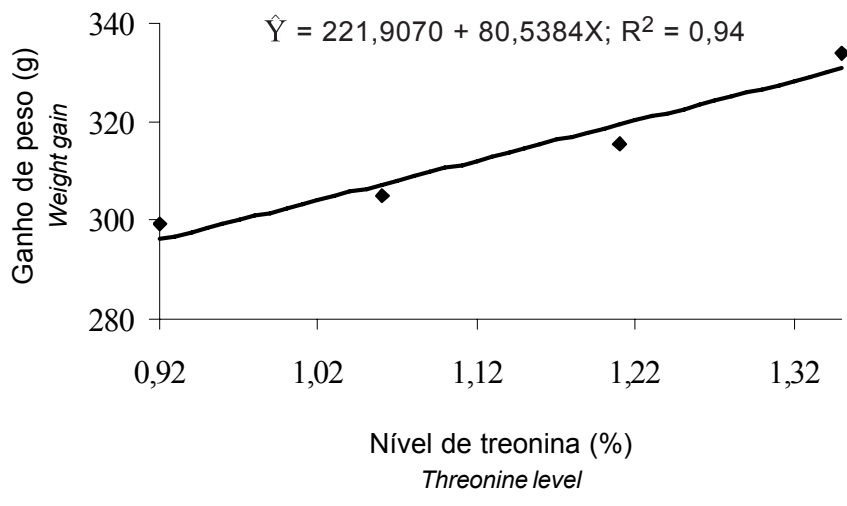

Figura 1 - Ganho de peso de tilápias-do-nilo alimentadas com rações contendo níveis crescentes de treonina.

Figure 1 - Weight gain of Nile tilapia fed diets with increasing levels of threonine.

A exigência de treonina pode variar com a espécie, como relatado por Keembiyehetty \& Gatlin (1997), em estudo com juvenis híbridos de striped bass, no qual observaram melhor conversão alimentar nos peixes alimentados com ração contendo $0,85 \%$ de treonina. Valor superior foi determinado por Ahmed et al. (2004), em pesquisa realizada com juvenis de carpa, em que melhor conversão alimentar foi verificada nos peixes alimentados com ração contendo $1,81 \%$ treonina. Neste estudo, a melhora na conversão alimentar foi confirmada pelo efeito associado do aumento no ganho de peso e da redução no consumo de ração.

Foi observado aumento linear $(\mathrm{P}<0,05)$ dos níveis de treonina sobre a taxa de eficiência protéica (Tabela 4) e a retenção de nitrogênio (Figura 2). Ahmed et al. (2004), em pesquisa realizada com alevinos de carpa, estimaram exigência de $1,78 \%$ de treonina na ração para melhor taxa de eficiência protéica. A elevada exigência de treonina nessa espécie, segundo os autores, está relacionada à sua baixa capacidade de utilização de aminoácidos sintéticos, por não apresentar acidez estomacal.

Os resultados obtidos nesta pesquisa demonstraram que o maior nível de treonina promoveu apenas redução no consumo de alimentos, não resultando em antagonismos entre os aminoácidos, o que pode ser confirmado pelos resultados da taxa de eficiência protéica e da porcentagem de retenção de nitrogênio, que aumentaram linearmente com a elevação nos níveis de treonina na ração. Além disso, neste estudo não foi observado aumento significativo do teor de gordura na carcaça dos peixes alimentados com a ração contendo os níveis mais elevados de treonina, comprovando que o aminoácido sintético foi utilizado pela tilápia para aumento do conteúdo de proteína corporal e não de gordura corporal. 
Tabela 4 - Desempenho de tilápias-do-nilo alimentadas com rações contendo níveis crescentes de treonina

Table 4 - Performance of Nile tilapia fed diets with increasing threonine levels

\begin{tabular}{|c|c|c|c|c|c|}
\hline \multirow[t]{2}{*}{$\begin{array}{l}\text { Variável } \\
\text { Variable }\end{array}$} & \multicolumn{4}{|c|}{$\begin{array}{c}\text { Nível de treonina }(\%) \\
\text { Threonine level }\end{array}$} & \multirow[b]{2}{*}{$\mathrm{CV}^{1}$} \\
\hline & 0,92 & 1,06 & 1,21 & 1,35 & \\
\hline $\begin{array}{l}\text { Peso inicial (g) } \\
\text { Initial weight }\end{array}$ & 36,22 & 38,20 & 38,82 & 39,02 & 4,63 \\
\hline $\begin{array}{l}\text { Peso final }(\mathrm{g}) \\
\text { Final weight }\end{array}$ & 335,68 & 343,21 & 354,23 & 372,81 & 4,78 \\
\hline $\begin{array}{l}\text { Ganho de peso }{ }^{2}(\mathrm{~g}) \\
\text { Weight gain }\end{array}$ & 299,46 & 305,01 & 315,41 & 333,79 & 5,67 \\
\hline $\begin{array}{l}\text { Consumo (g/peixe) } \\
\text { Feed intake/fish }\end{array}$ & 579,84 & 572,91 & 560,69 & 563,13 & 2,17 \\
\hline $\begin{array}{l}\text { Conversão alimentar } \\
\text { Feed:gain ratio }\end{array}$ & $2 \quad 1,94$ & 1,88 & 1,78 & 1,69 & 5,76 \\
\hline $\begin{array}{l}\text { Taxa de eficiência } \\
\text { protéica }{ }^{2} \\
\text { Protein efficiency ratio }\end{array}$ & 1,91 & 1,97 & 2,08 & 2,20 & 5,98 \\
\hline $\begin{array}{l}\text { Retenção de } \\
\text { nitrogênio }^{2}(\%) \\
\text { Nitrogen retention }\end{array}$ & 41,30 & 41,98 & 44,16 & 47,45 & 5,01 \\
\hline Peso do fígado $(\mathrm{g})$ & 6,21 & 6,58 & 6,40 & 6,82 & 5,19 \\
\hline $\begin{array}{l}\text { Liver weight } \\
\text { Índice hepato- } \\
\text { somático }\end{array}$ & 1,85 & 1,92 & 1,81 & 1,83 & 3,93 \\
\hline $\begin{array}{l}\text { Hepatic somatic index } \\
\text { Peso da carcaça }{ }^{2}(\mathrm{~g}) \\
\text { Carcass weight }\end{array}$ & 314,38 & 332,91 & 337,80 & 352,71 & 5,80 \\
\hline $\begin{array}{l}\text { Rendimento de } \\
\text { carcaça }(\%)\end{array}$ & 93,55 & 96,99 & 95,36 & 94,62 & 2,76 \\
\hline $\begin{array}{l}\text { Carcass yield } \\
\text { Peso do file } \\
\text { sem pele }{ }^{2}(\mathrm{~g})\end{array}$ & 125,65 & 132,42 & 135,78 & 140,79 & 5,64 \\
\hline $\begin{array}{l}\text { Fillet weight } \\
\text { Rendimento de } \\
\text { filé (\%) } \\
\text { Fillet yield }\end{array}$ & 37,37 & 38,58 & 38,36 & 37,77 & 2,99 \\
\hline
\end{tabular}

${ }^{1}$ Coeficiente de variação (Coefficient of variation).

2 Efeito linear (Linear effect) $(P<0,05)$ : ganho de peso (weight gain) $(P<0,065)$ $\left(\hat{Y}=221,9070+80,5384 X ; R^{2}=0,94\right) ;$ conversão alimentar (feed:gain ratio) $\left.(P<0,029) \hat{Y}=2,4952-0,5924 X ; R^{2}=0,99\right)$; taxa de eficiência protéica (protein efficiency ratio) $(P<0,034)\left(\hat{Y}=1,2760+0,6744 X ; R^{2}=0,99\right)$; retenção de nitrogênio (nitrogen retention) $(P<0,016)\left(\hat{Y}=27,0390+14,6929 X ; R^{2}=0,93\right)$; peso da carcaça (carcass weight) $(P<0,078)(\hat{Y}=240,237+82,7956 X$; $\left.R^{2}=0,96\right)$; peso dos filés (fillet weight) $(P<0,068)(\hat{Y}=95,4270+33,6423 X$; $\left.R^{2}=0,98\right)$.

Os dados obtidos neste estudo divergem dos achados de Yamada et al. (1981), que atribuíram o menor desempenho de peixes alimentados com rações contendo altos níveis de aminoácidos sintéticos à sua rápida absorção, que resulta em rápida elevação nos seus níveis plasmáticos, atingindo o pico anteriormente ao dos peixes alimentados com proteína intacta do alimento. Assim, ocorre maior catabolismo e menor aproveitamento dos aminoácidos sintéticos pelos peixes (Lim, 1993).

A retenção de nitrogênio parece ser o melhor parâmetro para determinação das exigências de aminoácidos pelos peixes, considerando-se que o ganho de peso não é resultado somente do acréscimo de proteína, mas também

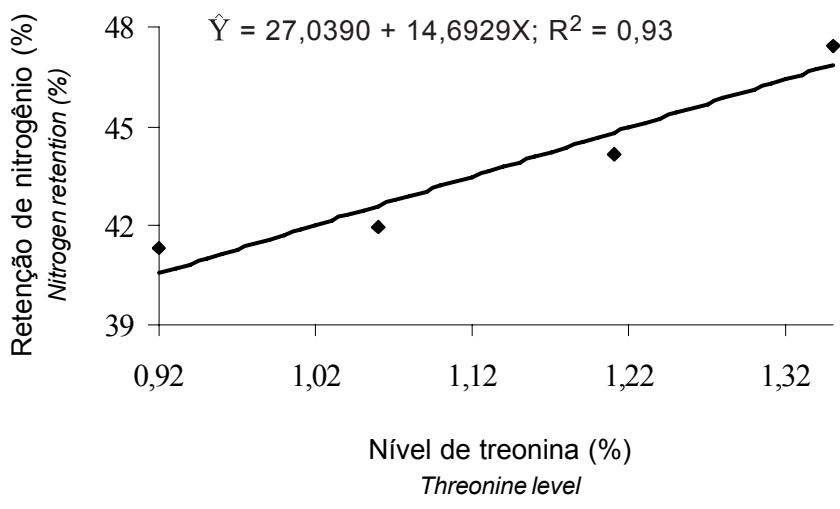

Figura 2 - Retenção de nitrogênio em tilápias-do-nilo alimentadas com rações contendo níveis crescentes de treonina.

Figure 2 - Nitrogen retention of Nile tilapia fed diets with increasing levels of threonine.

envolve a deposição de gordura na carcaça (Tibaldi \& Tulli, 1999). No entanto, neste estudo, o aumento nos níveis de treonina não elevou significativamente a deposição de gordura na carcaça.

Observou-se efeito linear $(\mathrm{P}<0,05)$ dos níveis de treonina sobre o peso da carcaça (Tabela 4) e o peso dos filés (Tabela 4). Em rações para aves e suínos, a suplementação de treonina está estreitamente relacionada ao aumento no rendimento de cortes nobres e à redução na deposição de gordura corporal (Blás et al., 2004). Isso não foi observado neste estudo, pois o aumento no peso da carcaça e dos filés esteve relacionado ao ganho de peso e não ao rendimento de carcaça ou de filé.

Não foram observados efeitos dos níveis de treonina sobre os teores de água, EE e proteína do filé (Tabela 4). A porcentagem de CIN no filé reduziu linearmente $(\mathrm{P}<0,05)$ com o aumento dos níveis de treonina na ração, o que provavelmente está relacionado ao aumento numérico nos níveis de EE no filé. Neste estudo, em razão do elevado desvio entre os dados de EE, ao contrário do observado para valores de cinzas no filé, não foram registradas alterações significativas. $\mathrm{O}$ incremento no conteúdo de gordura era esperado, pois houve maior ganho de peso à medida que se aumentou o nível de treonina.

Os níveis de treonina nas rações não influenciaram o custo da ração, o custo $/ \mathrm{kg}$ de ganho de peso e o custo $/ \mathrm{kg}$ ganho de filés (Tabela 6). Embora o custo do aminoácido sintético (L-treonina) tenha elevado o custo do quilograma da ração, quando considerado o custo em ração por quilograma de ganho de peso e o custo em ração por quilograma de ganho de peso em filés, a relação custo/benefício permaneceu praticamente constante. Em termos práticos, pode-se considerar que a redução no tempo de abate e a obtenção 
Tabela 5 - Composição química do filé de tilápias-do-nilo alimentadas com rações contendo níveis crescentes de treonina

Table 5 - Fillet chemical composition of Nile tilapia fed diets with increasing threonine levels

\begin{tabular}{|c|c|c|c|c|c|}
\hline \multirow[t]{2}{*}{$\begin{array}{l}\text { Variável } \\
\text { Variable }\end{array}$} & \multicolumn{4}{|c|}{$\begin{array}{c}\text { Nível de treonina (\%) } \\
\text { Threonine level }\end{array}$} & \multirow[b]{2}{*}{$\mathrm{CV}^{1}$} \\
\hline & 0,92 & 1,06 & 1,21 & 1,35 & \\
\hline $\begin{array}{l}\text { Água (\%) } \\
\text { Water }\end{array}$ & 78,73 & 78,44 & 78,67 & 78,67 & 0,88 \\
\hline $\begin{array}{l}\mathrm{PB}(\%) \\
\text { Crude protein }\end{array}$ & 18,38 & 18,49 & 18,56 & 18,36 & 2,58 \\
\hline $\begin{array}{l}\text { EE }(\%) \\
\text { Ether extract }\end{array}$ & 1,68 & 1,93 & 1,75 & 2,01 & 14,44 \\
\hline $\begin{array}{l}\mathrm{CIN}^{2}(\%) \\
A s h\end{array}$ & 1,21 & 1,14 & 1,02 & 0,95 & 6,53 \\
\hline
\end{tabular}

${ }^{1}$ Coeficiente de variação (coefficient of variation).

${ }^{2}$ Efeito linear (Linear effect) $(\mathrm{P}<0,05)$ : Cinzas (Ash) $(\mathrm{P}<0,005)(\hat{\mathrm{Y}}=1,7807$ $\left.0,6177 X ; R^{2}=0,99\right)$.

de peixes com maior peso vivo pode implicar maior benefício econômico ao produtor.

Os dados de literatura demonstram grandes variações nas exigências de treonina, como observado por Wilson et al. (1978), em juvenis de bagre do canal (0,50\%); por Akiyama et al. (1985), em juvenis de salmão chum (1,20\%); e por Santiago \& Lovell (1988), em alevinos de tilápia-do-nilo $(1,05 \%)$. As diferenças estão relacionadas à espécie, à idade, ao tipo de ração e aos alimentos utilizados, à influência dos fatores ambientais e à forma de interpretação dos dados.

Os resultados dessa pesquisa confirmam que a treonina é um aminoácido essencial para esta espécie e que sua inclusão em níveis acima do recomendado pelo NRC (1993) pode melhorar o ganho de peso, a conversão alimentar, a taxa de eficiência protéica, a retenção de nitrogênio e os pesos de carcaça e de filé, como verificado nos peixes que receberam ração com níveis mais elevados de treonina $(1,21$ e $1,35 \%)$.

A exigência de todos os aminoácidos essenciais descrita pelo NRC (1993) para a tilápia-do-nilo foi baseada em um único experimento, realizado com ração purificada, em condições laboratoriais, durante a fase de alevinos e com peixes com potencial genético inferior ao das atuais linhagens utilizadas. Assim, além de treonina, é necessária a determinação das exigências de metionina, lisina e triptofano em tilápias-do-nilo.

Os resultados deste estudo comprovaram que tilápiasdo-nilo em fase de terminação possuem exigência de 1,35\% de treonina na ração, correspondente a $74 \%$ da lisina, com base no conceito de proteína ideal. Quando expressa como porcentagem da proteína, a exigência estimada corresponde ao valor de $4,96 \%$ da PB (5,51\% da proteína digestível) da ração. Portanto, o valor estimado foi semelhante ao de
Tabela 6 - Custo/kg de ganho de peso $(R \$ / k g)$ e custo/kg de ganho de peso em filé $(R \$ / \mathrm{kg})$ de tilápia-do-nilo alimentadas com rações contendo níveis crescentes de treonina*

Table 6 - Cost $/ \mathrm{kg}$ of weight gain and cost $/ \mathrm{kg}$ of fillet weight of Nile tilapia fed diets with increasing threonine levels

\begin{tabular}{|c|c|c|c|c|c|}
\hline \multirow[t]{2}{*}{$\begin{array}{l}\text { Variável } \\
\text { Variable }\end{array}$} & \multicolumn{4}{|c|}{$\begin{array}{c}\text { Nível de treonina }(\%) \\
\text { Threonine level }\end{array}$} & \multirow[b]{2}{*}{$\mathrm{CV}^{1}$} \\
\hline & 0,92 & 1,06 & 1,21 & 1,35 & \\
\hline $\begin{array}{l}\text { Custo da ração }(\mathrm{R} \$ / \mathrm{kg}) \\
\text { Diet cost }\end{array}$ & 0,60 & 0,62 & 0,64 & 0,67 & 0,73 \\
\hline $\begin{array}{l}\text { Custo/kg de ganho } \\
\text { de peso (R } \$ / \mathrm{kg}) \\
\text { Cost } / \mathrm{kg} \text { of weight gain }\end{array}$ & 1,00 & 1,07 & 1,02 & 1,01 & 6,22 \\
\hline $\begin{array}{l}\text { Custo } / \mathrm{kg} \text { de ganho de } \\
\text { peso em filés ( } \mathrm{R} \$ / \mathrm{kg}) \\
\text { Cost } / \mathrm{kg} \text { of fillet weight }\end{array}$ & 2,67 & 2,86 & 2,65 & 2,68 & 8,81 \\
\hline
\end{tabular}

4,95\%, descrito para catla (Catla catla) (Ravi \& Devaraj, 1991) e ao de $4,5 \%$, para o milkfish e a carpa maior da Índia (Borlongan, 1991 e Ahmed et al., 2004, respectivamente).

\section{Conclusões}

A exigência de treonina para a tilápia-do-nilo em terminação é de $1,35 \%$, correspondente a $74 \%$ de lisina da ração (com base no conceito de proteína ideal) ou a 5,51\% da proteína digestível da ração.

\section{Literatura Citada}

AHMED, I.; KHAN, M.A.; JAFRI, A.K. Dietary threonine requirement of fingerling Indian major carp, Cirrhinus mrigala (Hamilton). Aquaculture Research, v.35, n.2, p.162-170, 2004.

AKIYAMA, T.; ARAI, S.; MURAI, T. Threonine, histidine and lysine requirements of chum salmon fry. Bulletin of the Japanese Society Fisheries Science, v.51, n.3, p.635639,1985

BORLONGAN, I.G. Arginine and threonine requirements of milkfish (Chanos chanos Fosskal) juveniles. Aquaculture, v.93, n.4, p.313-322, 1991.

BLÁS, C.; GARCIA, A.I.; CARABANÕ, R. Necessidades de treonina em animales monogástricos. In: CURSO DE ESPECIALIZACIÓN NECESIDADES DE TREONINA EN ANIMALES MONOGÁSTRICOS, 16., 2004, Madrid. Anais... Madrid: Universidad Politécnica de Madrid, 2004. p.22.

EUCLYDES, R.F. Manual de utilização do programa SAEG (Sistema para análises estatística e genética). Viçosa, MG: Universidade Federal de Viçosa, 1983. 59p.

FURUYA, W.M.; PEZZATO, L.E.; MIRANDA, E.C. et al. Coeficientes de digestibilidade e valores de aminoácidos digestíveis de alguns ingredientes pela tilápia do Nilo (Oreochromis niloticus). Revista Brasileira de Zootecnia, v.30, n.4, p.220230, 2001.

HENRY, Y.; SÈVE, B. Feed intake and dietary amino acid balance in growing pigs with special reference to lysine, tryptophan and threonine. Pig News Information, v.14, n.3, p.35-43, 1993.

JAUNCEY, K.; ROSS, B. A guide to tilapia feed and feeding. Scotland: University of Starling, 1982. $111 \mathrm{p}$. 
KEEMBIYEHETTY, C.N.; GATLIN, D.M. Dietary threonine requirement of juvenile hybrid striped bass (Morone chysops $X$ M. saxatilis). Aquaculture Nutrition, v.3, n.4, p.217-221, 1997.

LIM, C. Effect of dietary $\mathrm{pH}$ on amino acid utilization by shrimp (Penaeus vannamei). Aquaculture, v.114, n.3, p.293-303, 1993.

NATIONAL RESEARCH COUNCIL - NRC. Nutrient requirements of warm water fishes and shellfishes. Washington, D.C.: National Academy Press, 1993. 102p.

POPMA, T.J.; GREEN, B.W. Sex reversal of tilapia in earthen ponds. Aquaculture production manual. Alabama: Auburn University, 1990. 15p (Alabama Research and Development Series, 35).

RAVI, J.; DEVARAJ, K.V. Quantitative essencial amino acid requirements from growth of catla, Catla catla. Aquaculture, v.96, n.3, p.281-291, 1991.

SANTIAGO, C.B.; LOVELL, R.T. Amino acid requirements for growth of Nile tilapia. Journal of Nutrition, v.118, n.2, p.1540-1546, 1988 .

SILVA, S.S.; QUEIROZ, S. Análise de alimentos (métodos químicos e biológicos). 2.ed. Viçosa, MG: Universidade Federal de Viçosa, 2002. 235p.
TIBALDI, E.; TULLI, F. Dietary threonine requirement of juvenile European sea bass (Dicentrarchus labrax). Aquaculture, v.175, n.1-2, p.155-166, 1999.

WILSON, R.P.; ALLEN, O.W.; ROBINSON, A. et al. Tryptophan and threonine requirements of fingerling channel catfish. Journal of Nutrition, v.108, n.2, p.1595-1599, 1978.

YAMADA, S.; SIMPSOM, K.; TANAKA, Y. et al. Plasma amino acid changes in rainbow trout force-fed casein and corresponding amino acid mixture. Bulletin of the Japanese Society and Fisheres Science, v.47, n.4, p.1035-1040, 1981. 